\title{
The Porosity Evaluation during ECAP in Aluminium PM Alloy
}

\author{
J. Bidulská ${ }^{a, *}$, T. KVAČKAJ ${ }^{a}$, R. BidulskÝ ${ }^{b}$ AND M. ACTIS GRANDE ${ }^{b}$ \\ ${ }^{a}$ Department of Metals Forming, Faculty of Metallurgy, Technical University of Košice \\ Letná 9, 04200 Košice, Slovakia \\ ${ }^{b}$ Politecnico di Torino, Sede di Alessandria, 15 100, T. Michel, 5, Alessandria, Italy
}

\begin{abstract}
The main aim of this paper is to show porosity evolution during application of various processing conditions including pressing, sintering and equal channel angular pressure. An aluminium based powder $(\mathrm{Al}-\mathrm{Mg}-\mathrm{Si}-\mathrm{Cu}-\mathrm{Fe})$ was used as investigated material. After applying different pressing pressures (400 and $600 \mathrm{MPa}$ ), specimens were dewaxed in a ventilated furnace at $400{ }^{\circ} \mathrm{C}$ for $60 \mathrm{~min}$. Sintering was carried out in a vacuum furnace at $610^{\circ} \mathrm{C}$ for $30 \mathrm{~min}$. The specimens were processed by single equal channel angular pressure pass. A significant disadvantage of powder metallurgy processing methods is the presence of porosity. Pores act as crack initiators and, due to their presence, the distribution of stress is inhomogeneous across the cross-section and leads to reduction of the effective load bearing area. The equal channel angular pressure process, causing stress distribution in deformed specimens, made the powder particles to squeeze together to such an extent that the initially interconnected pores transform to small isolated pores. The proposed safety diagram includes the combined effect of stress and strain behaviour during equal channel angular pressure. The "safety line" eliminates and quantifies the effect of large pores as a potential fracture initiation sites with respect to the mechanical viewpoint.
\end{abstract}

PACS: 81.05.Bx, 81.07.Bc, 81.20.Ev, 81.40.-z

\section{Introduction}

Aluminium alloys generally show excellent properties such as high thermal and electrical conductivity, corrosion resistance, workability and especially light weight. These properties represent a good choice for the powder metallurgy (PM) industry, to produce new materials having unique capabilities, not currently available in any other powder metal parts. A better focus on mechanical properties is still needed for the further expansion of the PM market.

A significant disadvantage of the PM processing methods is the presence of porosity, as well as (in general) the highly inhomogeneous microstructures. The pores act as crack initiators and due to their presence, the distribution of stress is inhomogeneous across the cross section and leads to reduction of the effective load bearing area.

A further consolidation (secondary processing) is sometimes performed to remove any remaining porosity in order to improve the mechanical properties. Severe plastic deformation (SPD) processes may be used for this purpose [1-5].

In terms of economical reasons as well as secondary operation tasks, we are focused on the first pass of equal channel angular pressure (ECAP) process. Moreover, in the present markets there are questions over costs, and how to reduce them. ECAP produces a waste material. Because of increasing material costs, savings on raw materials directly, according to [6] influence the price of the finished part. There are some possibilities for saving ma-

\footnotetext{
* corresponding author; e-mail: jana.bidulska@tuke.sk
}

terial by multiple ECAP passes. Furthermore, the risk of damaging PM aluminium parts during subsequent passes can be minimised. Therefore, the main aim of this paper is to show the porosity evolution during the first ECAP pass in aluminium PM alloy in order to quantify the morphology and distribution of pores in the studied PM aluminium alloy.

\section{Experimental conditions}

A commercial ready-to-press aluminium based powders (ECKA Alumix 321) was used as material to be investigated $(\mathrm{Al}-0.95 \mathrm{Mg}-0.49 \mathrm{Si}-0.21 \mathrm{Cu}-0.07 \mathrm{Fe}$; wt \%). Unnotched impact energy specimens $55 \times 10 \times 10 \mathrm{~mm}^{3}$ (ISO 5754) were prepared at two different pressures, 400 and $600 \mathrm{MPa}$. The green compacts were weighed with an accuracy of $\pm 0.001 \mathrm{~g}$. The dimensions were measured with a micrometer calliper $( \pm 0.01 \mathrm{~mm})$. Specimens were dewaxed in a ventilated furnace (Nabertherm) at $400^{\circ} \mathrm{C}$ for $3600 \mathrm{~s}$. Sintering was carried out in a vacuum furnace (TAV) at $610^{\circ} \mathrm{C}$ for $1800 \mathrm{~s}$, with an applied cooling rate of $6 \mathrm{~K} / \mathrm{s}$ (specimen codes are $\mathrm{S} 4$ and $\mathrm{S} 6$, the number means pressure: $4-400 \mathrm{MPa}$ and $6-600 \mathrm{MPa}$ ). The ECAP (1 pass) was realized by hydraulic equipment at room temperature, which makes it possible to produce the maximum force of $1 \mathrm{MN}$ (specimen codes are E4 and E6). The die channel angle was $90^{\circ}$ and channels of diameter $10 \mathrm{~mm}$ in the cross-section.

Density (reciprocal value of total porosity) was measured using the Archimedes technique.

Specimens for microstructural characterization were prepared by means of a particular procedure aimed at avoiding modification of pore morphology. Optical char- 
acterization was carried out on the minimum of 10 different image fields by LEICA MPEF4 light microscopy. For the determination of porosity characteristics $100 \times$ magnification was used for specimens prepared by pressing and sintering and $500 \times$ for ECAPed specimens. Pores were recorded and processed by Leica Qwin image analysis system.

The fracture surfaces were investigated after tension test by INSTRON machine at room temperature.

\section{Results and discussion}

The 2-dimensional quantitative image analysis has gained importance in materials science and engineering. Several research studies have been successfully carried out using image analysis as an efficient instrument for the evaluation of microstructure characteristics. This methodology provides a reliable and reproducible statistical procedure for the classification of different microstructural features, including pores identification $[7,8]$. Quantitative image analysis of investigated material treats pores as isolated plane two-dimensional objects in solid surroundings.

Both the morphology and the distribution of pores have a significant effect on the mechanical behaviour of PM materials. In order to describe the dimensional and morphological porosity characteristics, the dimensional characteristic $D_{\text {circle }}$ and the morphological characteristics $f_{\text {shape }}$ and $f_{\text {circle }}$ as well as geometrical aspects have been identified as the most effective parameters [2]. The description of the parameters is reported in Fig. 1.

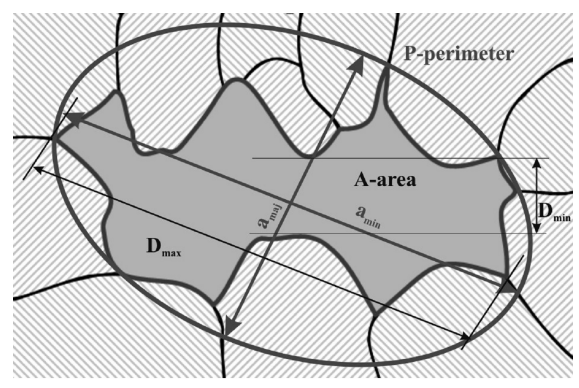

Fig. 1. Description of the pores parameters.

The parameters are as follows: $D_{\text {circle }}$ is the diameter of the equivalent circle that has the same area as the metallographic cross-section of the pore; $f_{\text {shape }}$ and $f_{\text {circle }}$ reflect the form of the pores; aspect is the ratio between major axis $\left(a_{\text {maj }}\right)$ and minor axis $\left(a_{\text {min }}\right)$ of an ellipse equivalent to the object.

Kubicki [9] provides a geometrical interpretation to the morphologic parameters

$$
\begin{aligned}
& f_{\text {shape }}=\frac{D_{\min }}{D_{\max }}=\frac{a}{b}[-], \\
& f_{\text {circle }}=\frac{4 \pi A}{P^{2}}[-],
\end{aligned}
$$

where $D_{\min }[\mu \mathrm{m}]$ is the parameter representing minimum of the Feret diameter; $D_{\max }[\mu \mathrm{m}]$ is the parameter representing maximum of the Feret diameter; $A\left[\mu \mathrm{m}^{2}\right]$ is the area of the metallographic cross-section of the pore; $P$ $[\mu \mathrm{m}]$ is the perimeter of the metallographic cross-section of the pore.

Kubicki further suggested that $f_{\text {shape }}$ and $f_{\text {circle }}$ are the parameters of the ellipse $\gamma$ and Eqs. (1) and (2) can be rewritten using

$$
\begin{aligned}
& A(\gamma)=\pi a b\left[\mu \mathrm{m}^{2}\right], \\
& P(\gamma)=\pi[1.5(a b)-\sqrt{a b}][\mu \mathrm{m}] .
\end{aligned}
$$

Then

$$
f_{\text {circle }}=\frac{4 f_{\text {shape }}}{\left[1.5\left(f_{\text {shape }}+1\right)-\sqrt{f_{\text {shape }}}\right]^{2}}[-] .
$$

Therefore, Eq. (5) constitutes a limit to the pore geometry. The ideal curve represents the minimum limit of pore geometry, which is given by $f_{\text {circle }}$. For a given $f_{\text {shape }}, f_{\text {circle }}$ may only be higher than the value corresponding to the equivalent smooth ellipse. The $f_{\text {shape }}$ represents pore elongation, while $f_{\text {circle }}$ depicts pore profile irregularity. Both parameters range between 0 and 1 , being equal to unity for a circular pore [10-14].

Previous investigations [12-17] show that sintering contributes to the formation of secondary porosity during transient liquid phase sintering (LPS) the swelling presented seems to be related to the amount of liquid generated (the deeper information about the LPS phenomenon is presented in review [18] and concerning aluminium PM alloys in $[19,20])$. The mix of primary, secondary and residual porosity is revealed by the mean values of pores size decreasing with increasing pressing pressure. Moreover, the coarse additive particle sizes leave large residual pores behind them. The ECAP process led to the decrease of pore sizes, Table.

TABLE

Porosity evaluation of the studied material.

\begin{tabular}{l|c|c|c|c|c}
\hline \hline & $\begin{array}{c}f_{\text {shape }} \\
{[-]}\end{array}$ & $\begin{array}{c}f_{\text {circle }} \\
{[-]}\end{array}$ & $\begin{array}{c}\text { Aspect } \\
{[-]}\end{array}$ & $\begin{array}{c}D_{\text {circle }} \\
{[\mu \mathrm{m}]}\end{array}$ & $\begin{array}{c}P \\
{[\%]}\end{array}$ \\
\hline $\mathrm{S} 4$ & 0.70 & 0.92 & $2.2 \pm 1.5$ & $31 \pm 4$ & 7.88 \\
$\mathrm{~S} 6$ & 0.69 & 0.92 & $2.2 \pm 0.8$ & $24 \pm 3$ & 7.18 \\
$\mathrm{E} 4$ & 0.67 & 0.91 & $1.9 \pm 0.4$ & $0.97 \pm 0.14$ & 1.69 \\
$\mathrm{E} 6$ & 0.67 & 0.91 & $1.8 \pm 0.5$ & $0.85 \pm 0.22$ & 1.36 \\
\hline \multicolumn{6}{l}{ total porosity }
\end{tabular}

Previous investigations [15-17] suggested that most of the pores diameter values are less than $1 \mu \mathrm{m}$. In fact, the small nanopores are rounder and because of their lower notch effect are less harmful for the mechanical behaviour. Moreover, the porosity evaluation is still under debate (with a limited amount of systematic experimental information in this area), especially in case of progressive processings - ECAP, equal channel angular rolling (ECAR), microwave sintering — where porosities play a critical role, especially in nanocrystalline materials (NC) and ultra fine grained (UFG) materials, according to Koch [21]. From the fracture mechanical point of view 
[22] and according to various authors [23-26], the size and the internal notch effect of the pores must be decisive for the material performance. Therefore, only pores larger than $1 \mu \mathrm{m}$ were investigated as potential fracture initiation sites and all smaller pores were excluded from further investigation.

Figure $2 \mathrm{a}$ and $\mathrm{b}$ presents the data depending on the mean value of pore diameter of the equivalent circle $D_{\text {circle }}$.

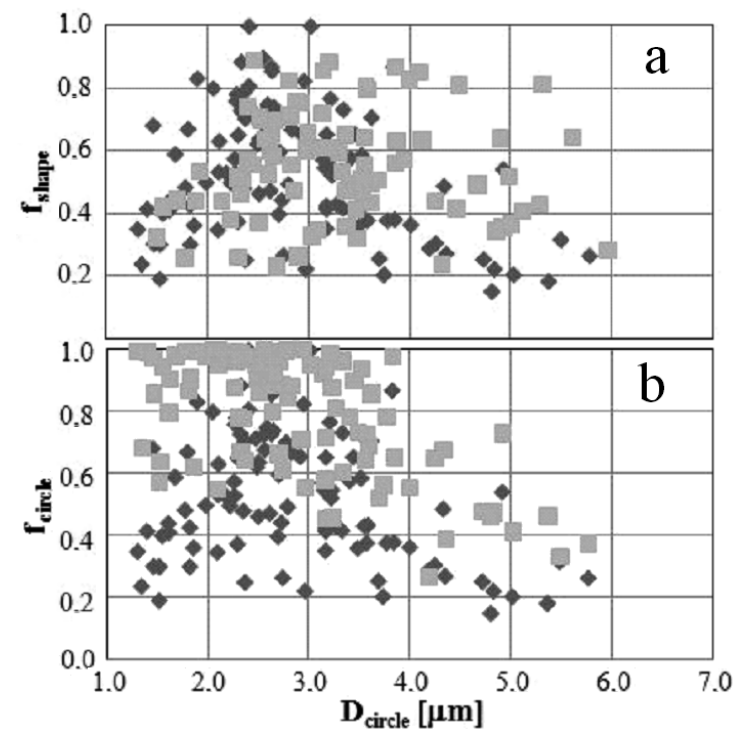

Fig. 2. (a) The $f_{\text {shape }}$ vs. $D_{\text {circle }}$ (b) the $f_{\text {circle }}$ vs. $D_{\text {circle }}$, E 4 - light points, E6 - dark points.

As shown in both Fig. 2a,b, lower pressing pressure (light points in figures) provides rounder pore structure and, on the other hand, more irregular shape. In terms of pore dimension, small pores evolve easily to a circular form, while large pores are very irregular and have a significant internal notch effect on mechanical properties.

The shape factor seems to be more suitable than the elongation factor to evaluate the evolution of pore morphology during ECAP process. This assumption is in good agreement with the results discussed in [11-15, 27].

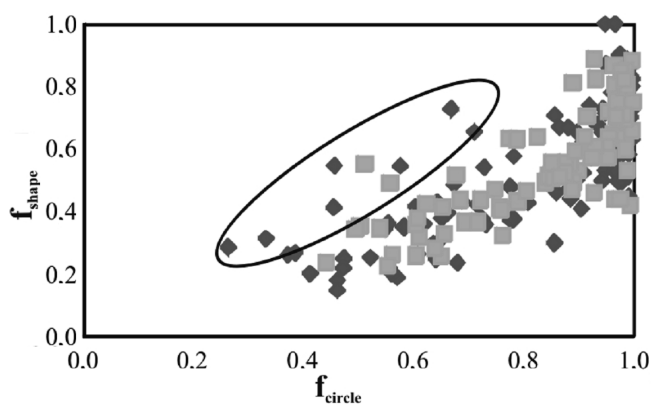

Fig. 3. The morphologic maps of studied material with points out of "ideal" range (give to the ellipse), E4 light points, E6 - dark points.
Figure 3 shows that more than $95 \%$ pores lie on the "ideal pore curve" [11], and that only $5 \%$ of large pores represent a potential fracture initiation site - with respect to the mechanical viewpoint (these points are in ellipse). Considering the stress and strain situation in workpiece during ECAP process, it is necessary to take into consideration a new geometrical factor - aspect, which represents the ratio between major axis and minor axis of ellipse equivalent to pore. It is well known that ECAP is able to align particles; basically the material located near to the surface of a workpiece in the exit channel, just beyond the inside channel angle, experiences a state of hydrostatic tension [28]. The high levels of both these compressive and tensile stresses, combined with the high localized shear strains, may be sufficient to promote high rates of pore nucleation and elimination. The applied mean stress, known as the hydrostatic stress, induces new plasticity-driven densification mechanisms, as well as a stress-assisted diffusion mechanism [29]. Both mechanisms enhance the densification rate. Other mechanisms such as grain boundary sliding and grain rotation may also play a role in densification. The mean stress is responsible for the radial growth rate of pores and for equivalent stress which correlates more closely with changes in pore shape as well has a stronger effect on the elliptic pores. The shear component of the applied stress causes particle rearrangement and the collapse of large pores. The particle rearrangement and macroscopic deformation of pores increase the number of particle contacts.

The main benefit from the safety diagram (Fig. 4) is an overall view of pore crack initiators during ECAP including the combined effect of stress and strain behaviour. The "safety line" eliminates and quantifies the effect of large pores as a potential fracture initiation sites with respect to the mechanical viewpoint.

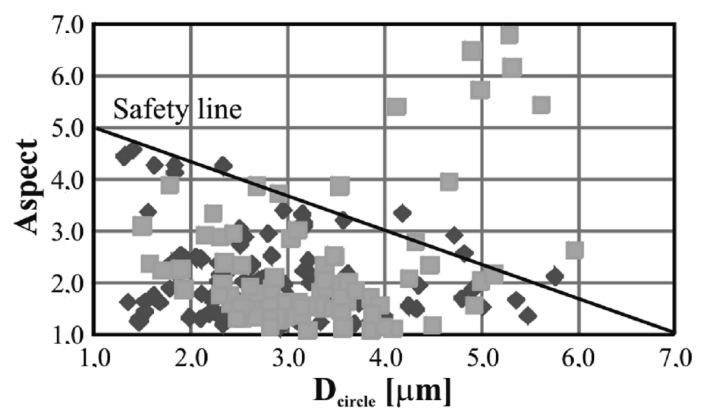

Fig. 4. Safety diagram for studied material, E4 - light points, E6 - dark points.

The construction of proposed "safety line" is done by fractographic interpretation and microstructure identification of weak sites in studied aluminium PM alloys. The underlying mechanisms are not well understood. The possible lack of understanding of the fracture/microstructure overview of porosity phenomena as a potential fracture initiation sites is due to limited knowledge of de- 
formation/fracture mechanisms for proposed UFG PM microstructures. There appears to be no direct experimental confirmation in the published literature of the operation of these processes. Critical to further advances in this topic will be systematic studies of the influence of important variables such as strain hardening, localized shear, grain boundaries, triple junction, second phases and other. However, they also raise interesting questions and concerns that require substantial further inquiry.

During the first ECAP pass the pores become closed and separated. When the pore dimensions (in terms of the ratio between major axis and minor axis of ellipse equivalent to pore) are reduced to under "safety line" they can be treated as isolated stress-raisers in a continuous matrix of solid metal. Therefore, the overall properties depend largely on the toughness and strength of the matrix material and the influence of pores can be neglected.

\section{Conclusion}

1. A significant disadvantage of PM processing methods is the presence of porosity. Pores act as crack initiators and, due to their presence, the distribution of stress is inhomogeneous across the cross-section and leads to reduction of the effective load bearing area.

2. The ECAP process, causing stress distribution in deformed specimens, made the powder particles to squeeze together to such an extent that the initially interconnected pores transform to small isolated pores.

3. The new geometrical factor - aspect - considered the stress and strain situation in workpiece during ECAP process.

4. The proposed safety diagram includes the combined effect of stress and strain behaviour during ECAP. The "safety line" eliminates and quantifies the effect of large pores as a potential fracture initiation sites with respect to the mechanical viewpoint.

\section{Acknowledgments}

This work was financially supported by the projects: APVV SK-PL-0011-09, VEGA 1/0385/11 and VEGA $1 / 0359 / 11$.

\section{References}

[1] X. Wu, W. Xu, K. Xia, Mater. Sci. Eng. A 493, 241 (2008).

[2] J. Bidulská, T. Kvačkaj, R. Kočiško, R. Bidulský, M. Actis Grande, Mater. Sci. Forum 667-669, 535 (2011).

[3] R. Kocisko, P. Zubko, J. Durisin, M. Molnarova, A. Kovacova, M. Kvackaj, J. Bacso, Chem. Listy 104, 330 (2010).

[4] M. Kvačkaj, T. Kvačkaj, A. Kováčová, R. Kočiško, J. Bacsó, Acta Metall. Slovaca 16, 84 (2010).
[5] R. Kočiško, T. Kvačkaj, J. Bidulská, M. Molnárová, Acta Metall. Slovaca 15, 228 (2010).

[6] S. Haltner, A. Wehrli, M. Gassmann, Metal Powder Rep. 61, 17 (2011).

[7] T. Rausch, P. Beiss, Ch. Broeckmann, S. Lindlohr, R. Weber, Proc. Eng. 2, 1283 (2010).

[8] M. Jeandin, S. Rupp, J. Massol, Y. Bienvenu, Mater. Sci. Eng. 77, 139 (1986).

[9] B. Kubicki, Powder Metall. 38, 295 (1995).

[10] R.T. DeHoff, E.H. Aigeltinger, Proceedings of Perspectives in Powder Metallurgy, Plenum Press, New York 1970, Vol. 5, p. 81.

[11] T. Marcu Puscas, M. Signorini, A. Molinari, G. Straffelini, Mater. Charact. 50, 1 (2003).

[12] R. Bidulský, J. Bidulská, M. Actis Grande, High Temp. Mater. Process. 28, 337 (2009).

[13] J. Bidulská, R. Kočiško, R. Bidulský, M. Actis Grande, T. Donič, M. Martikán, Acta Metall. Slovaca 16, 4 (2010).

[14] J. Bidulská, T. Kvačkaj, R. Kočiško, R. Bidulský, M. Actis Grande, T. Donič, M. Martikán, Acta Phys. Pol. A 117, 864 (2010).

[15] J. Bidulská, T. Kvačkaj, R. Kočiško, R. Bidulský, M. Actis Grande, J. Electr. Eng.-Slovaca 28, 308 (2010).

[16] M. Actis Grande, R. Bidulský, J. Bidulská, T. Kvačkaj, Adv. Mater. Res. 189-193, 2838 (2011).

[17] J. Bidulská, T. Kvačkaj, R. Bidulský, M. ActisGrande, L. Lityńska-Dobrzyńska, J. Dutkiewicz, Chem. Listy 105, s471 (2011).

[18] R.M. German, P. Suri, S.J. Park, J. Mater. Sci. 44, 1 (2009).

[19] G.B. Schaffer, T.B. Sercombe, R.N. Lumley, Mater. Chem. Phys. 67, 85 (2001).

[20] J.M Martin, F Castro, J. Mater. Process. Technol. 143-144, 814 (2003).

[21] C.C. Koch, J. Metastable Nanocryst. Mater. 18, 9 (2003).

[22] P. Beiss, M. Dalgic, Mater. Chem. Phys. 67, 37 (2001).

[23] A. Salak, V. Miskovic, E. Dudrova, E. Rudnayova, Powder Metall. Inter. 6, 128 (1974).

[24] G.F. Bocchini, Int. J. Powder Metall. 22, 185 (1986).

[25] A. Salak, Ferrous Powder Metallurgy, Cambridge International Science Publishing, Cambridge 1995, p. 453.

[26] S. Saritas, R.J. Causton, W.B. James, A. Lawley, Adv. Powder Metall. Part. Mater. 10, 51 (2001).

[27] L. Fuentes-Pacheco, M. Campos, Sci. Sinter. 41, 161 (2009).

[28] R.Y. Lapovok, D. Tomus, J. Mang, Y. Estrin, T.C. Lowe, Acta Mater. 57, 2909 (2009).

[29] Nanostructured Materials: Processing, Properties and Potential Applications, Ed. C.C. Koch, Noyes Publications, New York 2002. 